\title{
Obituary: Professor Malcolm Lader
}

\author{
Ian Stolerman ${ }^{1}$ - Alyson Bond ${ }^{1} \cdot$ Martin Jarvis $^{2} \cdot$ H. Valerie Curran ${ }^{3}$
}

Published online: 21 October 2020

(C) Springer-Verlag GmbH Germany, part of Springer Nature 2020

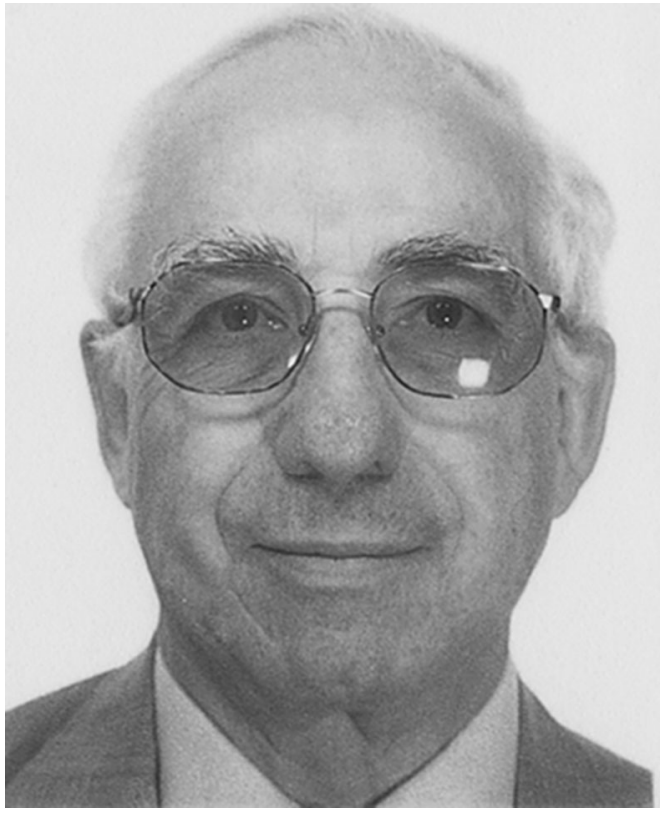

In the early days of clinical psychopharmacology, Malcolm Lader did much to lay the foundations of the subject in Britain. Primarily a psychiatrist, he had diverse interests that ranged through physiology, psychology, pharmacology and law in

H. Valerie Curran

v.curran@ucl.ac.uk

Ian Stolerman

ian.stolerman@kcl.ac.uk

Alyson Bond

alyson.bond@kcl.ac.uk

Martin Jarvis

martin.jarvis@ucl.ac.uk

1 Institute of Psychiatry, Psychology and Neuroscience, London, UK

2 University College, London, UK

3 Clinical Psychopharmacology Unit, University College London, Gower Street, London, UK addition to medicine. His love of learning was life-long. Indeed he obtained an honours degree in Law in 2006 precisely 50 years after his first degree in medicine.

His early studies with Alyson Bond led to the quantification of subjectively experienced drug effects and their objective physiological correlates. The clinical studies for which Malcolm is best known were on benzodiazepine dependence, initially carried out with Hannes Petursson. Despite early preclinical evidence of their potential for inducing dependence, marketing techniques emphasised their clinical advantages over the earlier barbiturates while downplaying, and sometimes denying, the risk of addiction. Malcolm started an outpatient clinic at the Maudsley Hospital for anxious patients, the majority of whom had been taking benzodiazepines for years. He and Hannes systematically studied these patients and provided strong evidence for the occurrence of BDZ dependence when used in the long term at normal therapeutic doses. Malcolm did not simply publish these findings but wrote many articles for broader audiences and engaged with the media to raise the public's awareness of BDZ dependence. This led to him becoming a persona non grata in some quarters. His work had a major impact upon the extent of BDZ prescriptions across the globe.

Malcolm went on to identify alternatives to BDZs in treating anxiety and conducted early randomised controlled trials with buspirone, antihistamines and selective serotonin reuptake inhibitors. He also acknowledged the importance of psychological treatments.

Malcolm made major contributions to the development of psychopharmacology by his enthusiastic support of societies. He was President of the Society for the Study of Addiction (SSA) for 10 years and encouraged the growth of its publication, the British Journal of Addiction, which evolved into Addiction, the premier international journal in the field. The British Association for Psychopharmacology (BAP) came into existence in the 1970s, and he helped shape its growth, playing a major role in the controversy that its initially limited scope engendered. He was BAP President from 1986 to 1988.

In his home town of Liverpool, Malcolm was a star medical student, gaining many prizes. The day he qualified, he moved 
to London and in 1960 was given a research post in psychopharmacology by Professor Schild at University College London, where he also completed his PhD. During this period, he provided valuable guidance to Channi Kumar and Ian Stolerman, members of Hannah Steinberg's group, who were beginning a series of experiments on morphine dependence. He also worked with Lorna Wing on the effects of barbiturates and BDZs in healthy participants, research that led to his MD.

In the late 1960s, he moved to the newly built Institute of Psychiatry (IoP) as a Medical Research Council scientist with support for a small team through a series of 5 yearly "grantsin-aid". This enabled him to attract clinicians and psychologists to his research unit, including Hannes Petursson, Alyson Bond, Brian Toone, Flavio Kapzinski, Anna Higgit, Cosmo Hallstrom, Susan Golombok and Val Curran. The unit administrator for most of its lifetime was the wonderful Lily Hughes. Malcolm always welcomed visiting students (of any age) from abroad. In turn he would often visit them in their home coun- tries, part of his eternal love for travelling across the world.

Malcolm sat on numerous government committees and for many years was Chair of the Ministry of Defence Research Ethics Committee and sat on the Home Office Advisory Council on the Misuse of Drugs (1981-2001). In 1996 he was awarded an OBE and 3 years later was elected a Fellow of the Academy of Medical Sciences.

Malcolm's academic output was huge with hundreds of peer-reviewed articles, many books and other types of publications. His research had enormous clinical impact, and many patients benefited from his insistence on the need to accurately assess the potential risks as well as benefits of all psychotropic drug treatments. He is survived by his wife Susan, their 3 daughters and 7 grandchildren.

Publisher's note Springer Nature remains neutral with regard to jurisdictional claims in published maps and institutional affiliations. 